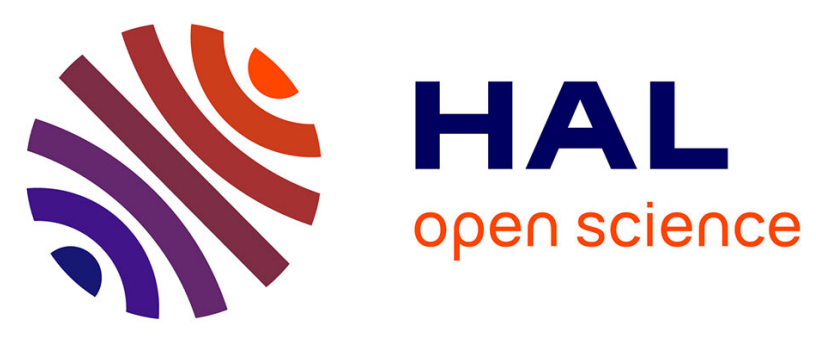

\title{
Environmental benchmarks for buildings: needs, challenges and solutions-71st LCA forum, Swiss Federal Institute of Technology, Zürich, 18 June 2019
}

Rolf Frischknecht, Maria Balouktsi, Thomas Lützkendorf, Annette Aumann, Harpa Birgisdottir, Elmar Grosse Ruse, Alexander Hollberg, Matti Kuittinen,

Monica Lavagna, Antonín Lupišek, et al.

\section{To cite this version:}

Rolf Frischknecht, Maria Balouktsi, Thomas Lützkendorf, Annette Aumann, Harpa Birgisdottir, et al.. Environmental benchmarks for buildings: needs, challenges and solutions-71st LCA forum, Swiss Federal Institute of Technology, Zürich, 18 June 2019. International Journal of Life Cycle Assessment, 2019, 24 (12), pp.2272-2280. 10.1007/s11367-019-01690-y . hal-03318986

\author{
HAL Id: hal-03318986 \\ https://hal.science/hal-03318986
}

Submitted on 11 Aug 2021

HAL is a multi-disciplinary open access archive for the deposit and dissemination of scientific research documents, whether they are published or not. The documents may come from teaching and research institutions in France or abroad, or from public or private research centers.
L'archive ouverte pluridisciplinaire HAL, est destinée au dépôt et à la diffusion de documents scientifiques de niveau recherche, publiés ou non, émanant des établissements d'enseignement et de recherche français ou étrangers, des laboratoires publics ou privés. 


\section{Environmental benchmarks for buildings: needs, challenges and solutions-71st LCA forum, Swiss Federal Institute of Technology, Zürich, 18 June 2019}

Rolf Frischknecht1 \& Maria Balouktsi2 \& Thomas Lützkendorf2 \& Annette Aumann3 \& Harpa Birgisdottir4 \& Elmar Grosse Ruse5 \& Alexander Hollberg6 \& Matti Kuittinen7 \& Monica Lavagna8 \& Antonín Lupišek9 \& Alexander Passer10 \& Bruno Peuportier11 \& Livia Ramseier1 \& Martin Röck10 \& Damien Trigaux12 \& Dora Vancso1 $13^{1}$

\section{Abstract}

Purpose The 71st LCA forum was held on 18 June 2019 in Zurich, Switzerland, to discuss the current status and future plans of environmental benchmarking for buildings in view of the $1.5^{\circ} \mathrm{C}$ target stipulated in the Paris Agreement. The Paris Agreement requires a significant reduction in greenhouse gas emissions, in fact net zero by 2050 . One of the priority areas is the building stock, as it is an important source of greenhouse gas emissions. COP23, the International Energy Agency (IEA) and an increasing number of countries are extending their consideration from aspects such as energy consumption and emissions from building operation to the manufacture of construction materials and building construction. The event offered an excellent platform to exchange ideas and thoughts on existing and planned environmental benchmarking schemes for buildings.

Methods The one day event dealt at first with life cycle assessment (LCA) approaches applied in European, Asian, Australasian and American countries to assess the environmental performance of buildings. Within a round robin test, organised within the IEA EBC (Energy in Building and Communities) Annex 72 project, 22 organisations from 21 countries assessed the environmental performance of one identical building, the be 2226 office building located in Lustenau, Austria. The materials, the building technologies and the energy consumption were kept constant. This allowed to identify the main differences in LCA data used and LCA methodology applied in the national contexts. In the LCA forum, eight organisations presented the current state or future plans of an environmental benchmarking system in their home country. The systems were characterised in terms of scope, in particular (a) which types of buildings are covered; (b) which life cycle stages are included; (c) which building elements and which operational energy uses are considered; and (d) which environmental impacts are addressed. Furthermore, the default reference service life and the main source of LCA data were specified and the current or planned benchmark values for greenhouse gas emissions of residential buildings were reported.

Results and discussion The round robin test revealed the LCA background data as one major source of difference in assessment results. Methodological and modelling choices were less important except for the Danish assessment, which applies a comparatively long reference study period (80 years for office buildings, 120 years for residential buildings) and considering future changes in the electricity mix towards $100 \%$ renewables to describe the operational electricity demand during the lifetime of the building. Most benchmarking systems presented are applied on new and retrofit residential, office and school buildings. Other use types such as shops, restaurants, universities or hospitals are covered only in few or just one country. The greenhouse gas emission benchmark for residential buildings (construction and operation) revealed a significant gap between the current

\footnotetext{
1 treeze Ltd., Uster Switzerland

2 Karlsruher Institut fur Technologie, Karlsruhe Germany

3 Stadt Zurich, Zurich Switzerland

4 Statens Byggeforskningsinstitut, Copenhagen Denmark

5 World Wildlife Fund, Zürich Switzerland

6 Eidgenossische Technische Hochschule Zurich, Zurich Switzerland

7 Ministry of the Environment, Helsinki Finland

8 Politecnico di Milano Dipartimento di Architettura Ingegneria delle

Costruzioni e Ambiente Costruito, Milan Italy

9 Ceske Vysoke Uceni Technicke v Praze, Prague Czech Republic

10 Technische Universitat Graz, Graz Austria

11 MINES ParisTech Center for Energy efficiency of Systems, Paris

France

12 Katholieke Universiteit Leuven, Leuven The Netherlands

$13 \mathrm{~W} / \mathrm{E}$, Amsterdam The Netherlands
} 
level of the building benchmarks on one hand and the target of net zero $\mathrm{CO}_{2}$-eq emissions derived from the 1.5 ${ }^{\circ} \mathrm{C}$ scenarios of IPCC on the other. An online inquiry carried out among the audience during the event showed a preference for a per capita overall budget of $500 \mathrm{~kg} \mathrm{CO}_{2}$-eq per year to derive greenhouse gas emission benchmarks for buildings and that life cycle-based benchmarks for buildings should be legally binding. Conclusions The 71st LCA forum on environmental benchmarks for buildings showed that the experts present acknowledge the net zero $\mathrm{CO}_{2}$ emission target derived from the $1.5{ }^{\circ} \mathrm{C}$ scenarios. Several countries have expertise and experience in assessing the environmental impacts of buildings. However, the current (mostly voluntary) benchmarking schemes are way too weak to support the building sector in contributing significantly to the required $\mathrm{CO}_{2}$ emission turn off. The outlook given by several speakers showed that the current benchmarks will likely be tightened and oriented on the planetary boundaries and on the scientifically defined $\mathrm{CO}_{2}$ emission budgets rather than on the technical or economic feasibility. Finally, the responsibility of governments for defining environmental requirements and targets was stressed. The event, the exchange of ideas and the discussions helped to nurture and hopefully accelerate the developments in the construction sector of the home countries of the experts and government representatives. These developments will contribute to a society whose environmental impacts remain within the carrying capacity of our planet.

\section{Introduction and overview}

The 71st LCA forum was opened with a welcome address given by Rolf Frischknecht (treeze, Switzerland). He presented the Project IEA EBC Annex 72 BAssessing life cycle related environmental impacts caused by buildings ${ }^{\wedge}$ within the Technology Collaboration Programme 1 Energy in Buildings and Communities (EBC). $1^{2}$ This project deals with a harmonisation of life cycle assessment (LCA) methodology applied on buildings, guidelines on the design processes and implementation of LCA information in planning tools such as Building Information Model (BIM), the compilation of building case studies illustrating the methodologies and approaches as well as guidelines on the creation of LCA databases tailored for the construction sector. The project involves more than 40 experts in 25 countries from four different continents.

Benchmarking regarding the environmental footprinting gets more and more attention. Sessions dedicated to this topic were and will be organised at scientific conferences such as IALCCE 20182 (Lützkendorf and Balouktsi 2018) or SBE Graz 2019.3 Furthermore, the International Standardisation Organisation is preparing an international standard, ISO 21678 BSustainability in buildings and civil engineering works-Indicators and benchmarks-Principles for the development and use of benchmarks^ .

Elmar Grosse Ruse (WWF, Switzerland) highlighted the necessity of limiting global warming to $1.5^{\circ}$ over preindustrial temperature levels. The estimated carbon budget for any $1.5^{\circ}$ scenario is so small that global greenhouse gas (GHG) emissions must be reduced to net-zero within very few decades. In the case of Switzerland, that means that-taking into account the principle of global equity-domestic emissions should be net-zero by 2040 the latest (Vieli et al. 2017).

Thus, from now on, domestic emissions must be reduced by roughly 4\% p.a. based on 1990 levels. For the building sector, an even faster GHG reduction is advised for two reasons (IEA 2019): In no other sector, the potential for lowering the energy need below business-as-usual-level seems as high as in the building stock. And technology solutions for de-carbonating

\footnotetext{
21 See http://annex72.iea-ebc.org/, accessed 3 June 2019. 2 See http://www.ialcce2018.org/\#/minisymposia, accessed 6 June 2019. 3 See https://www.tugraz.at/events/sbe19/program/\#c213632, accessed 6 June 2019.
} 
the operation phase of buildings already exist and are competitive in terms of life cycle costs. What is needed is an effective regulatory framework for a rapid take-up of these technologies. Technologies and construction materials for reducingGHG emissions associated with the construction phase of buildings (grey emissions) are by far less common place today and, thus, must be quickly developed and scaled up. In a first session, the results of the environmental assessment of one specific building using national approaches were presented (Section 2). The speakers of the second and third sessions showed environmental benchmarking systems in operation or planned in various European countries (Section 3).

In the fourth sessions, further building-related environmental benchmark systems were presented (Section 4). The insights from the panel discussion are presented in Section 5 and the conclusions drawn during the LCA forum in Section 6.

\section{Comparing national building assessment methods}

Martin Röck (Technical University Graz, Austria) presented the case study office building be2226, its BIM and the life cycle inventory (LCI). The building, located in Lustenau,

Austria, represents an innovative low-tech concept without active heating or cooling systems. The building's heating demand is covered by solar gains as well as heat emitted from occupants and electronic devices. For cooling and regulation of indoor air quality, the building relies on sensing temperature and $\mathrm{CO} 2$ levels and automated opening and closing of window side panels for natural ventilation. The building is constructed mostly from brick and concrete (even external walls are composed of one load bearing and one insulating brick layer). In general, the building's layout aims for high flexibility in use by applying, for example, an open plan and a raised flooring system within which the minimalistic technical installations are distributed. The building's BIM model was modelled by Martin Röck based on documentation provided by the architects. Next to additional data on, for example, material properties and life cycle scenarios, the BIMmodel provided a valuable data source, mostly for extracting element and material quantities for LCA (Röck et al. 2018). The be 2226 building and the related information had already been used as a case study in the PEF4Buildings study for the European Commission (VITO et al. 2018) as well as in a project on environmental benchmarks for buildings (Tschuemperlin and Frischknecht 2018) and now served as a reference building for testing application of national LCA methods within IEA EBC Annex 72.

Livia Ramseier (treeze, Switzerland) provided a comparison of 22 LCAs of the office building be 2226 carried out within the international research project IEA EBC Annex 72 (Frischknecht et al. 2019). The Annex experts applied, if available, their national LCA approach4 on the predefined material and energy demand for the office building and assessed the primary energy demand, greenhouse gas emissions and other environmental impacts.

The reference study period was in 15 approaches 50 years, in six approaches 60 years and Denmark applied a reference study period of 80 years. Furthermore, the different approaches included different life cycle stages. The different assessments of the be 2226 building resulted 
in GHG emissions between 10 and $71 \mathrm{~kg} \mathrm{CO} 2-\mathrm{eq} / \mathrm{m} 2 \mathrm{a}$. Depending on the assessment, either the product stage or the operational energy was responsible for most of the GHG emissions. In the product stage, the differences in the GHG emissions are on one side due to the variances in GHG emissions per kg building material, which differ up to a factor of 6 , and on the other side due to differences in the reference study periods applied. The variances in the operational energy use stage of this particular building reflect the different GHG intensity of the national electricity mixes.

\section{Existing benchmark systems regarding environmental impacts of buildings}

Bruno Peuportier (MinesParisTech, France) presented French benchmarks. The EQUER method is a design tool. The corresponding benchmarks provide lower and upper values of environmental indicators, enabling a designer to know how his project performs compared to best and worst practice. Three categories are considered: individual and collective housing, and office buildings. Haussmannian buildings from the 1880 s, social housing from the $1960 \mathrm{~s}$, renovated or not, and new construction with and without photovoltaic electricity production have been studied in order to derive 12 indicator intervals based upon ecoinvent 2.2 and considering 100 years reference study period (200 years for the Haussmannian building). For instance, $\mathrm{CO} 2$ emissions vary between 10 and $120 \mathrm{~kg}$ per year and per heated $\mathrm{m} 2$. The benchmarks are being updated using ecoinvent 3.4 and new environmental indicators, particularly damage indicators on human health and ecosystems. Similar benchmarks have been established on singlefamily houses and office buildings ( 50 years reference study period). The next building regulation, planned for 2020, will include LCA. Benchmarks are being defined in terms of building types (individual or collective housing, offices, others), climate zone, number of parking places and the area of building. At the moment, the average threshold is around $40 \mathrm{~kg}$ $\mathrm{CO} 2$ per year and per $\mathrm{m} 2$ of floor area.

Annette Aumann (City of Zürich, Switzerland) presented the Swiss benchmark system for building SIA 2040 Energy Efficiency Path. The citizens of Zurich voted in 2008 to implement the targets of the 2000-Watt Society in their constitution (Stadt Zürich 2017). The long-term goal is to achieve a sustained primary energy use of 2000 watts per person and emissions of no more than 1 ton of $\mathrm{CO} 2$ equivalent per person and year. The SIA Energy Efficiency Path (SIA 2040) as a technical specification is the basis for the implementation of an intermediate goal for the year 2050 for the building sector (SIA 2017). The SIA 2040 focuses on setting targets for nonrenewable primary energy use and greenhouse gas emissions for six building categories for both new buildings and refurbishments, taking construction, operation and induced mobility into account. As an owner's representative, the SIA Energy Efficiency Path is estimated as an instrument to check if the City of Zurich meets the goals with its building activities. Thanks to the overall energetic view, it helps the City of Zurich to find a balanced strategy to accomplish. Damien Trigaux (EnergyVille/KU Leuven/VITO, Belgium) presented the Belgian environmental benchmarks 
for buildings which are currently being developed in the context of a research project by EnergyVille, KU Leuven and VITO (Trigaux et al. 2019). In that research project, the benchmark values are derived from the combination of a top-down approach based on global environmental goals and policy targets and a bottom-up approach based on a statistical analysis of the building stock. The proposed benchmarking system focuses in a first stage on residential buildings, including new constructions and refurbishments, but will be extended in future to other building typologies. The benchmark scope covers the whole building life cycle, including embodied and operational impacts. In terms of impact indicators, an aggregated score (expressed in environmental cost) is used, combined with indicative benchmark values for individual impact indicators. In the short term, the developed benchmark values will be used as decision support in order to allow architects and building stakeholders to position themselves in the market. Besides an implementation in the Belgian LCA webtool,5 integration in labels and sustainability rating tools are also possible. In the medium term, legal requirements will be introduced, departing from limit or reference values, which will gradually evolve towards more ambitious (target) benchmark values.

Harpa Birgisdottir (Danish Building Research Institute, Aalborg University, Denmark) presented the benchmarking system in use for DGNB certification and the system under development for the potential future (voluntary) requirements in building regulation. An adapted version of the DGNB system has been in use for voluntary certification in Denmark since 2012 with benchmarks for offices, residential, schools and hospitals. The initial benchmarks were based on the German DGNB benchmarks, but somewhat adapted. As a result of a political vision introduced in 2014 mentioning a voluntary sustainability class in the Building Code, development of a national LCA tool for buildings was initiated, and the first version of LCAbyg was launched in 2015

(Birgisdottir and Rasmussen 2019). With the introduction of the use of the LCAbyg tool for DGNB certification in 2018, resulting in substantial changes in the methodological approach, the first Danish benchmarks for offices and residential buildings were introduced based on previous certified buildings. These are based on bottom-up approach from 16 office cases (Rasmussen and Birgisdottir 2018) and only 7 for residential (Rasmussen et al. 2019). A new benchmark system for the potential future (voluntary) requirement in the building code is under development, and which proposal is expected to be presented in the end of year 2019. The preliminary focus will be on offices and residential buildings, and by extending the pull of data from 16 offices and 7 residential to about 22 offices and 34 residential buildings. The same approach will most likely be adopted by DGNB in Denmark. The work related to the development of the benchmarks includes revisions of different important methodological aspects within the benchmarking system, such as the length of the RSP, service life for different building elements and completeness of the LCI.

Antonín Lupíšek (Czech Technical University in Prague, Prague, Czech Republic) presented a bottom-up approach in the existing national sustainability certification scheme SBToolCZ and ongoing development of a national top-down 
benchmark for greenhouse gases (GHG) for new residential buildings. SBToolCZ (Vonka et al. 2013) currently covers new construction of multifamily residential buildings (2010, revised 2013), single-family houses (2013), offices (2016), schools (2017) and kindergartens (2018). The certification consists of assessment of environmental, social and economic areas and of non-scored evaluation of site selection. The core environmental criteria include indicators based on a simplified evaluation of phases A1-A3 (production) and B6 (operation): primary energy, greenhouse gas emissions, acidification, eutrophication, ozone depletion and photochemical ozone creation potential. In addition, other 7-8 criteria (depending on typology) are evaluated (greenery, fresh water consumption, water management, materials, certified products, land use, onsite renewables, efficient cooling and ecological value of site). The benchmarks were derived bottom-up from case studies based on designs of new buildings. The certification has been voluntary so far and the number of certified buildings had been rather low. Since 2018, it is required for funding of selected publicly developed buildings. The certification method is developed by the Czech Technical University in Prague, and certificates are prepared by authorised persons and verified by third parties (Building Research Institute -

Certification Company, Ltd. and Technical and Test Institute for Construction Praha, SOE). A new top-down benchmark for new single- and multi-family residential buildings is under development. The reference unit will be one person (building user) instead of $\mathrm{m}_{2}$ of a building. The benchmark is based on GHG emission gap for climatic goals of 1.5 and $2.0^{\circ} \mathrm{C}$. A first version was already piloted in several case studies, and revision and finalization is planned for 2020 .

Thomas Lützkendorf (KIT, Karlsruhe, Germany) presented the benchmarks used in Germany since 2008 as measures for the assessment of impacts on environment and the use of resources in the life cycle of buildings (König and De Cristofaro 2012). Requirements for the description of the building as well as for the modelling of its life cycle are derived from international and European standards. The German Sustainable Building Council (DGNB) has developed benchmarks for various types of use. 6 The public sector-using a specific sustainability assessment system known as BNB (BMUB 2019a) - has developed benchmarks for new and renovated office, educational and laboratory buildings. So far, the basis for the development of benchmarks has been statistical analyses of building examples and individual type representatives (archetypes) in combination with the consideration of legal requirements for energy performance (bottomup). The derivation of target values from global or national targets or sector-related budgets (top-down) is still under discussion. The German Climate Action Plan 2050 contains a target value for the building sector to limit GHG emissions in the form of a budget. In Germany, benchmarks are in principle used in connection with the application of the different sustainability certification systems and to support the design process. The application of sustainability assessment systems for new building projects and renovation projects is voluntary. One exception is the assessment of new and renovated federal government buildings. Here, the application of the sustainability assessment system BNB is mandatory. The uniform data basis for BNB and DGNB is oekobau.dat (BMUB 2019b). A 
reference study period of 50 years is used.

Dora Vansco (W/E, the Netherlands) presented the Dutch

framework for the LCA of buildings with the MPG method.

Next to this national method, there is a national LCA database

for building materials (NMD) available. The NMD provides

the input data for national harmonised assessment tools to

calculate environmental impact of entire buildings. One of

these certified calculation tools is GPR building. An MPG

calculation is compulsory for building permit requests for

new office buildings and new houses larger than $100 \mathrm{~m} 2$. A

limit value of MPG $\leq 1$ is in place. In the GPR building tool, all types of buildings, new and existing, can be assessed. All relevant life cycle stages are included: production, building, use, demolition and processing, except operational energy.

The MPG calculation can be used (1) to comply with regulations;

(2) for sustainability certification (GPR building); and

(3) as a design tool. The NMD and the MPG exist since 2012, predecessors were being used already in the 1990s. The NMD

is managed by Stichting Bouwkwaliteit (SBK), a publicprivate organisation. For the future, several developments

are underway: the limit value of 1 will probably be lowered, as it is very easily reached. Also efforts are underway to allow for a better evaluation of circularity scores.

Matti Kuittinen (Ministry of Environment, Finland) presented Finland's plan planning to implement mandatory carbon footprinting of buildings by 2025. As a policy measure, life cycle carbon budgets are also planned for buildings. The latter can be understood as normative Bbenchmark^ ${ }^{\wedge}$ system, which ismade possible through a national assessmentmethod. Finland's scope includes the same building categories that need to be given an energy certificate. This will, however, apply in the beginning only to new buildings. Later on, the scope is planned to be extended to cover those refurbishment or renovation projects that require a building permission and/ or fall within the scope of the energy declaration. The basis for the benchmark derivation is not yet defined. A linkage to national climate policies is however planned, while feasibility studies of a cost and climate optimal levels of the benchmark value are currently being investigated. Thus, the final benchmarking system may include top-down and bottom-up features. The carbon footprinting of buildings will be a standalone process, which is parallel with the energy certification of buildings. Later on, further environmental indicators are planned to be integrated to it. The system will be a government-operated one. Certain parts of it may be delegated to other public authorities as well.

An overview of national benchmarking systems described above is shown in Table 1. Most countries apply

benchmarking on new and refurbished residential buildings. Germany and Finland cover a very broad spectrum of different building types. The greenhouse gas emission benchmark for residential buildings (between 9 and $20 \mathrm{~kg} \mathrm{CO} 2$-eq/m2a; construction, operation and end of life) revealed a significant gap between the current level of the building benchmarks on one hand and the target of net-zero $\mathrm{CO}_{2}$-eq emissions derived from the $1.5^{\circ} \mathrm{C}$ scenarios of IPCC on the other (UNFCCC 2015). A compilation of the main characteristics of the national benchmarking systems described above as well as the results of an inquiry about the application, the effect and the future plans of national benchmarking systems is provided 
on the LCA forum website (http://www.lcaforum.ch/

Downloads/DF71/tabid/123/Default.aspx).

\section{Further building-related environmental benchmark systems}

Alexander Hollberg (ETH Zürich, Switzerland) presented a dual benchmark approach to support decision-making in the design process of new residential buildings in Switzerland. Life cycle assessment (LCA) is increasingly used during the design phase to evaluate the environmental performance of buildings. However, designers and clients find it difficult to interpret the results and use them to improve the building design. Therefore, performance levels or benchmarks that provide design guidance are needed. The main concept presented here consists in combining top-down targets on the building level with bottom-up benchmarks on element level (Hollberg et al. 2019). The top-down target is based on a global budget of $1 \mathrm{t} \mathrm{CO}_{2}$-equivalent per person and year. This overall target is divided into different sectors following the Swiss Energy Efficiency Path SIA 2040 (SIA 2017) to define top-down benchmarks for embodied and operational GHG emissions. To calculate the bottom-up benchmarks for embodied GHG emissions of individual building elements (walls, roof, etc.), the national building component catalogue is weighted with statistical data on the market share of materials. Assuming a log-normal distribution, the target values for the 5 th percentile (top 5\%) are calculated. This approach can be extended to further building types in the future. Furthermore, it can be applied in other national contexts, as long as a component catalogue representing the typical construction types and market share data are available.

Monica Lavagna (Politecnico di Milano, Italy) presented the study called BBasket of Products-housing, in the context of the research BIndicators and targets for the reduction of the environmental impact of EU consumption^ ${ }^{\wedge}$ (EC-JRC 2014), developed by European Commission Joint Research Centre. The project was financially supported by the DGEnvironment of the European Commission. The aim of the study is to quantify the average environmental impacts related to current housing stock in Europe and to define reference values (Lavagna et al. 2018). Hence, the LCA methodology has been applied to 24 statistically based models of dwellings (multi-family house and single-family house), representative of the EU housing stock in 2010. The benchmarks have been calculated taking into consideration the number of dwellings (clustered per typology, year of construction and climate zone) related to each representative model. System boundaries include production, construction, use (energy and water consumption), replacement and end-of-life phases of each dwelling. The environmental LCIAwas carried out using the ILCD impact assessment method and recently updated to the Environmental Footprint method (Sala et al. 2019). EU average annual environmental impact per person, per dwelling, per dwelling type and per $\mathrm{m}_{2}$ were calculated. The final results could be used as a baseline scenario for testing eco-innovation scenarios and setting targets toward impact reduction, as illustrated in Allacker et al. (2019).

\section{Panel discussion}


Alexander Passer (Technical University Graz, Austria)

chaired the panel discussion and presented the results of a live and online survey among the participants. According to the majority of the 33 participants answering the questions, the benchmarks should be developed top-down, e.g. derived from planetary boundaries (see Fig. 1). The appropriate starting point of a personal overall emission budget seems to be between 0 and 1 ton of $\mathrm{CO}_{2}$-eq per capita and year (see Fig. 2).

Finally, a vast majority of the participants think that life cyclebased greenhouse gas emission benchmarks should become part of the legal requirements (see Fig. 3).

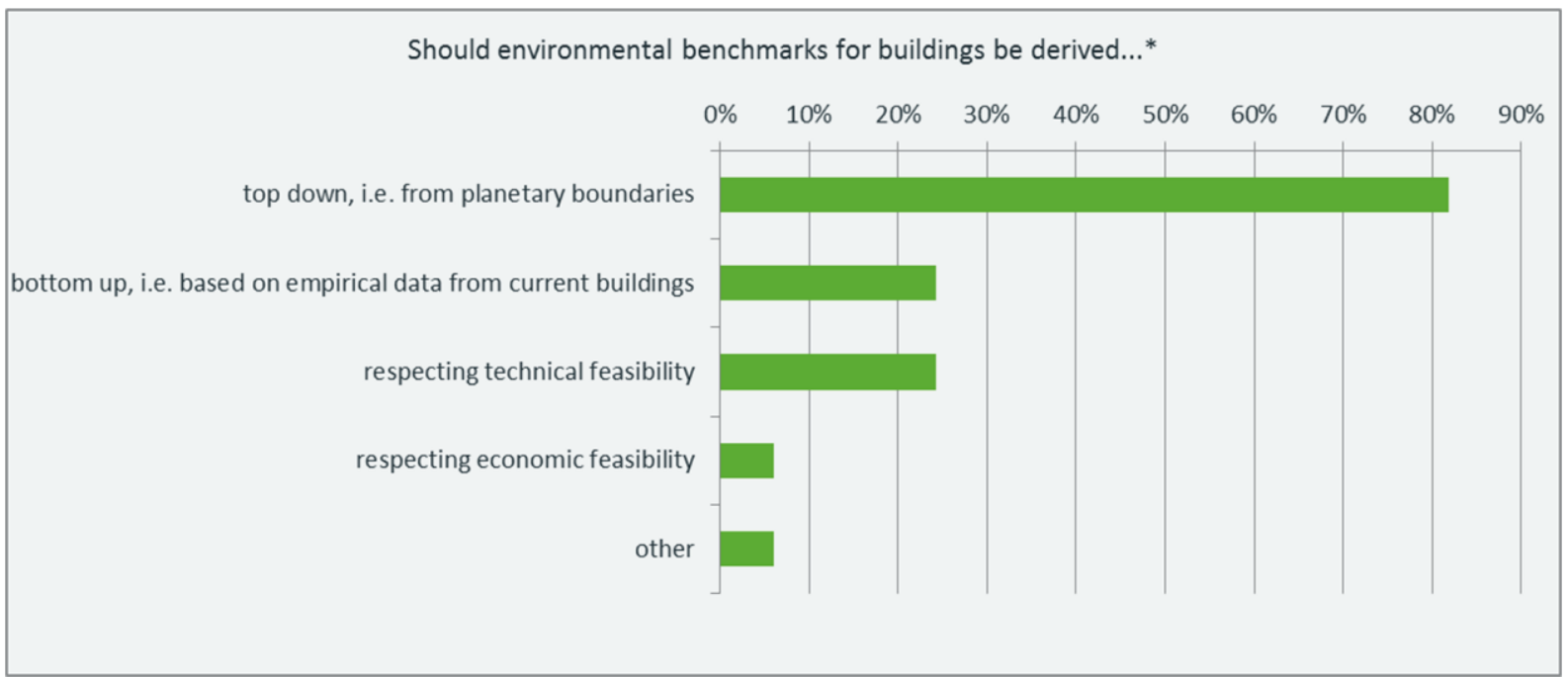

Fig. 1 Question related to the general approach of how to derive environmental benchmarks for buildings (asterisk: multiple answers allowed)

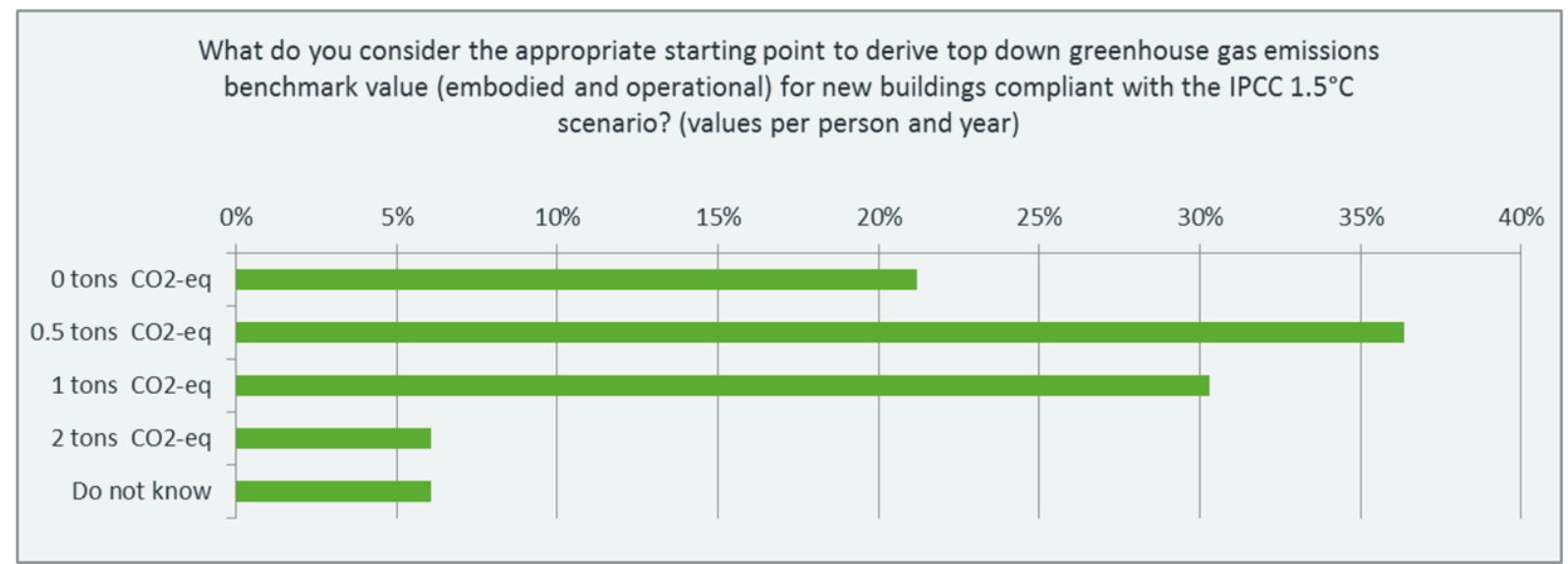

Fig. 2 Question related to the annual greenhouse gas emission budget per person and year 


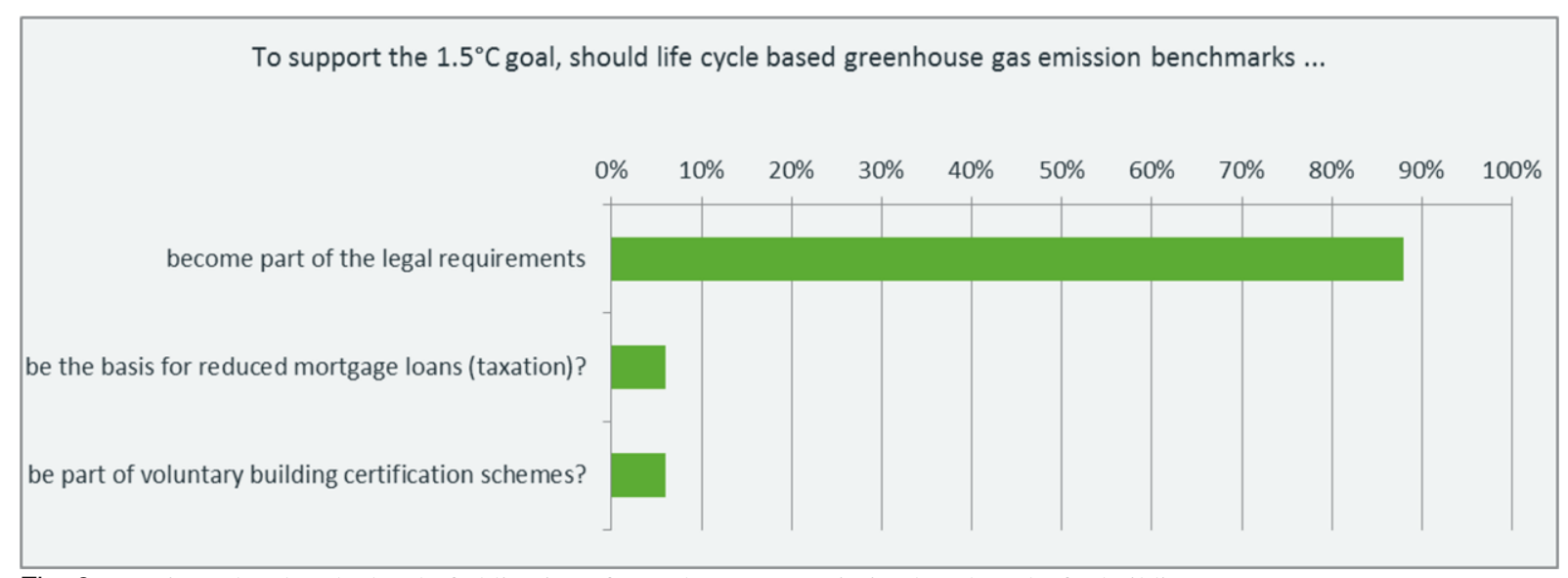

Fig. 3 Question related to the level of obligation of greenhouse gas emission benchmarks for buildings

During the panel discussion, the experts outlined that legally binding benchmarks for buildings are required to achieve the net-zero $\mathrm{CO}_{2}$ emission target. However, the experts stressed as well the importance of voluntary benchmark systems until legally binding benchmarks are in place or even as preferable option. During the LCA DF 71, different types of benchmarks (i.e. initial or life cycle related) and different indicators (e.g. greenhouse gas emissions or primary energy demand) were presented. The experts stated that it is valid to ask for a full life cycle-related benchmark system.

Furthermore, they agree that climate change is not the only environmental problem that should be addressed by a benchmark system, but in most of the current systems it is the starting point. Single-score environmental indicators such as eco-points according to the ecological scarcity method may serve as a monitoring indicator to avoid problem shifting. There were different opinions on the level of aggregation of the results among the experts. Those recommending singlescore indicators emphasised the easier and often better understandable communication of a single-value result instead of possibly contradicting results from a broader set of indicators. On the other hand, it was argued that reporting environmental impacts in a disaggregated way is very helpful in identifying environmental trade-offs when optimising construction products, building elements or buildings.

The last discussion point concerned the often mentioned reproach that the data quality/availability is not yet ready to be included as part of benchmarks in a legislation. The experts discussed that the data available now is suitable to be used for benchmarking and that an improvement of data quality and availability comes along with a legally binding benchmark (e.g. more producers need to provide LCAs and EPDs for their products). An industry representative raised the concern that different EPD providers have different data requirements and thus introduce barriers to trade, which affects most of all small companies. Furthermore, there is an urgent need to improve the transparency of data in EPDs. An expert concurred with the need to improve the transparency and that the block chain technology might be a possible solution to this issue. The call for more harmonisation is addressed by IEA EBC Annex 72, where the goal inter alia is to provide harmonised methodology guidelines.

\section{Conclusions}


In his concluding remarks, Rolf Frischknecht summarised the three main insights of the day. Firstly, the speakers as well as the audience acknowledged the $1.5^{\circ} \mathrm{C}$ target and the subsequent need for a substantial reduction of greenhouse gas emissions in the next decades. They are ready to take up this challenge the construction sector is exposed to. Secondly, the presentations and the panel discussion showed that greenhouse gas emissions are an important benchmarking indicator and that this indicator is being used side by side with further environmental impact indicators. Finally, a tendency is observed that benchmarks are more and more defined from top-down, deriving environmental benchmarks for buildings, for example, from global planetary boundaries.

\section{References}

Allacker K, Castellani V, Baldinelli G, Bianchi F, Baldassarri C, Sala S (2019) Energy simulation and LCA for macro-scale analysis of ecoinnovations in the housing stock. Int J Life Cycle Assess 24(6):9891008

Birgisdottir H, Rasmussen FN (2019) Development of LCAbyg: a national life cycle assessment tool for buildings in Denmark. In:

CESB 19, Prague, 2019. IOP Conference Series Earth and

Environmental Science

BMUB (2019a) Assessment system for sustainable building/BNB.

German Federal Ministry for the Environment Nature

Conservation Building and Nuclear Safety. http://www.

nachhaltigesbauen.de/sustainable-building-english-speakinginformation/ assessment-system-for-sustainable-building.html.

BMUB (2019b) ÖKOBAUDAT. German Federal Ministry for the

Environment Nature Conservation Building and Nuclear Safety. https://www.oekobaudat.de/en.html. Accessed 5 June 2019

EC-JRC (2014) Indicators and targets for the reduction of the environmental impact of EU consumption: basket-of-products indicators and prototype targets for the reduction of environmental impact of EU consumption. European Commission, Joint Research Centre, Institute for Environment and Sustainability, Ispra, Italy Frischknecht R, Birgisdottir H, Chae CU, Lützkendorf T, Passer A, Alsema E, Balouktsi M, Berg B, Dowdell D, García Martínez A, Habert G, Hollberg A, König H, Lasvaux S, Llatas Olive C, Nygaard Rasmussen F, Peuportier B, Ramseier L, Röck M, Soust Verdaguer B, Szalay Z, Bohne RA, Bragança L, Cellura M, Chau CK, Dixit M, Francart N, Gomes V, Huang L, Longo S, Lupíšek A, Martel J, Mateus R, Ouellet-Plamondon C, Pomponi F, Ryklová P, Trigaux D, Yang W (2019) Comparison of the environmental assessment of an identical office building with national methods.

Paper presented at the Sustainable built environment D-A-CH conference 2019, Graz, Austria

Hollberg A, Lützkendorf T, Habert G (2019) Top-down or bottom-up?how environmental benchmarks can support the design process. Building and Environment 153 (April):148-157

IEA (2019) Perspectives for the clean energy transition. IEA, Paris König H, De Cristofaro ML (2012) Benchmarks for life cycle costs and life cycle assessment of residential buildings. Build Res Inf 40(5): $558-580$

Lavagna M, Baldassarri C, Campioli A, Giorgi S, Dalla Valle A, Castellani V, Sala S (2018) Benchmarks for environmental impact of housing in Europe: definition of archetypes and LCA of the residential building stock. Build Environ 145:260-275

Lützkendorf T, Balouktsi M (2018) Principles for the development and use of benchmarks for life-cycle related environmental impacts of buildings. In: IALCCE-Konferenz: Life-cycle analysis and assessment in civil engineering - towards an integrated vision, Ghent, 28.31.10.2018 2018

Rasmussen FN, Birgisdottir H (2018) Life cycle assessment benchmarks for Danish office buildings. Paper presented at the IALCCE 2018, 6th International Symposium on Life-Cycle Civil Engineering, Ghent, Belgium 
Rasmussen FN, Ganassali S, Zimmerman RK, Lavagna M, Campioli A, Birgisdóttir H (2019) LCA benchmarks for residential buildings in Denmark and Italy-learnings from comparing two different contexts. Build Res Inf 47:833-849

Röck M, Hollberg A, Habert G, Passer A (2018) LCA and BIM: visualization of environmental potentials in building construction at early design stages. Build Environ 140:153-161

Sala S, Benini L, Beylot A, Castellani V, Cerutti A, Corrado S, Crenna E, Diaconu E, Sanyé-Mengual E, Secchi M, Sinkko T, Pant R (2019)

Consumption and consumer footprint: methodology and results. Indicators and assessment of the environmental impact of EU consumption. Publications Office of the European Union, Luxembourg. https://doi.org/10.2760/15899

SIA (2017) Merkblatt 2040: SIA-Effizienzpfad Energie. Schweizerischer Ingenieur- und Architektenverein (SIA), Zürich

Stadt Zürich (2017) Gemeindeordnung der Stadt Zürich

Trigaux D, Allacker K, Debacker W (2019) Critical analysis of environmental benchmarks for buildings. Paper presented at the Sustainable Built Environment D-A-CH conference 2019, Graz, Austria

Tschuemperlin L, Frischknecht R (2018) Lessons learned from establishing an environmental benchmark for buildings in Switzerland. Paper presented at the IALCCE 2018, 6th International Symposium on Life-Cycle Civil Engineering, Ghent, Belgium

UNFCCC (2015) Adoption of the Paris Agreement, vol FCCC/CP/2015/

L.9/Rev.1, Paris

Vieli B, Fussen D, Müller M (2017) CO2-Budget der Schweiz. Zollikon

VITO, Leuven KU, Graz TU (2018) PEF4Buildings—study on the application of the PEF method and related guidance documents to a newly office building (ENV.B.1/ETU/2016/0052LV); Deliverable D3: report on PEF study of newly built office building. https://doi. org/10.2779/23505

Vonka M, Hájek P, Lupíšek A (2013) SBToolCZ: sustainability rating system in the Czech Republic. Int J Sustain Build Technol Urban Dev 4(1):46-52 